\title{
Association between miR-212-3p and SOX11, and the effects of miR-212-3p on cell proliferation and migration in mantle cell lymphoma
}

\author{
YUYANG TIAN $^{1 *}$, LI WANG $^{2 *}$, YANMING ZHANG $^{2}$, LIANQIAO LI $^{1}$, \\ YINGYING FEI ${ }^{3}$, XINGXIA ZHANG ${ }^{2}$ and GUOQIANG LIN ${ }^{2}$ \\ ${ }^{1}$ Department of Hematology, Hainan Cancer Hospital, Haikou, Hainan 571000; Departments of \\ ${ }^{2}$ Hematology and ${ }^{3}$ Radiotherapy, Huai'an Hospital Affiliated to Xuzhou Medical College and \\ Huai'an Second People's Hospital, Huai'an, Jiangsu 223002, P.R. China
}

Received July 23, 2020; Accepted May 21, 2021

DOI: $10.3892 / \mathrm{ol} .2021 .12970$

\begin{abstract}
To the best of our knowledge, the effect of miR-212-3p on sex-determining region Y-box 11 (SOX11) expression has not been previously investigated and how this effect affects cell proliferation and migration in lymphoma remains unclear. The present study aimed to assess the association between microRNA-212-3p (miR-212-3p) and SOX11, and the effects of miR-212-3p on cell proliferation and migration in mantle cell lymphoma. Cancer tissue and corresponding paracancerous tissue samples were collected from 65 patients with mantle cell lymphoma. The mRNA expression levels of miR-212-3p and SOX11 were analyzed using quantitative PCR, and SOX11 protein expression was determined using western blotting. Following transfection, the miR-212-3p mimic group exhibited a significantly lower SOX11 mRNA and protein expression than the miR-NC group. After $48-72 \mathrm{~h}$ of transfection, cell proliferation in the miR-212-3p mimic group was significantly lower than that in the miR-NC group. Furthermore, the miR-212-3p mimic group exhibited significantly lower cell invasion and significantly higher apoptosis than the miR-NC group. The current results suggested that miR-212-3p inhibited lymphoma cell proliferation and migration, and promoted their apoptosis by specifically regulating SOX11. Therefore, miR-212-3p may serve as a novel therapeutic target and marker for lymphoma.
\end{abstract}

Correspondence to: Dr Guoqiang Lin, Department of Hematology, Huai'an Hospital Affiliated to Xuzhou Medical College and Huai'an Second People's Hospital, 62 Huaihan South Road, Huai'an, Jiangsu 223002, P.R. China

E-mail: snwvc8@163.com

${ }^{*}$ Contributed equally

Key words: microRNA-212-3p, sex-determining region Y-box 11, JeKo-1 cell, Z-138 cell, mantle cell lymphoma, proliferation, migration, apoptosis

\section{Introduction}

Mantle cell lymphoma (MCL), which is a non-Hodgkin's lymphoma type, is a refractory hematological cancer with a poor prognosis (1-3) due to its high drug resistance and it has a survival period of $1-2$ years after relapse $(4,5)$. Therefore, effective and highly safe therapies that specifically target molecular MCL are imperative (6).

Sex-determining region Y-box 11 (SOX11), which belongs to the SOX family, is an intron-lacking gene that is highly expressed in various types of cancer, including breast cancer, ovarian cancer and MCL (7-11). It promotes angiogenesis and tumor cell migration and metastasis by mediating the expression of platelet-derived growth factor $\alpha(12,13)$. Recently, the targeting roles of microRNAs (miRNAs/miRs) have attracted great attention. miRNAs can regulate mRNAs by binding to the 3'-untranslated region of the target mRNA, thereby regulating gene expression, and miRNA dysregulation often leads to cancer $(14,15)$. miR-212-3p is a miRNA that inhibits the proliferation of blood cancer cells; however, it is minimally expressed in adult T-cell leukemia/lymphoma and plasmablastic lymphoma $(16,17)$. It has been revealed that miR-212-3p acts as a tumor suppressor in numerous types of cancer, such as osteosarcoma (18), glioblastoma (19) and intrahepatic cholangiocarcinoma (20). Overall, SOX11 seems to have a promoting effect on the growth of lymphoma, whereas miR-212-3p expression is low in various cancer cells. However, to the best of our knowledge, the effect of miR-212-3p on SOX11 expression has not been previously investigated, and how this effect affects cell proliferation and migration in lymphoma remains unclear. Therefore, the present study aimed to assess the association between miR-212-3p and SOX11, and the effects of miR-212-3p on cell proliferation and migration in MCL.

\section{Materials and methods}

Tissue collection. Cancerous and corresponding paracancerous tissues ( $5 \mathrm{~mm}$ distance from cancerous tissue) were collected from 65 patients with MCL who underwent surgery at Huai'an Hospital Affiliated to Xuzhou Medical College and 
Huai'an Second People's Hospital (Huai'an, China) between November 2016 and November 2019. The cancerous tissues of the patients were all taken from the lymph node tissues, and the adjacent tissues were dominated by normal B lymphocytes (such as tunicular lymphocytes) (Table I). Patients diagnosed with MCL at the aforementioned hospital, without other major diseases, and with relatively complete clinical data were included in the present study. Conversely, patients who had received any radiotherapy and chemotherapy before the study, or who presented with diseases that could affect the study results or with severe hepatic dysfunction were excluded. The Ethics Committee of Huai'an Hospital Affiliated to Xuzhou Medical College and Huai'an Second People's Hospital approved the present study. All patients and their families were informed of the study, and they signed informed consent forms before the commencement of the study.

Main reagents and instruments. Human MCL cells (JeKo-1 and Z-138 cells) and DMEM were obtained from Hunan Fenghui Biotechnology Co., Ltd. Fetal bovine serum (FBS) was obtained from Thermo Fisher Scientific, Inc. Cell apoptosis assay kit and Lipofectamine ${ }^{\circledR} 3000$ were obtained from Sigma-Aldrich (Merck KGaA). TRIzol ${ }^{\circledR}$ was obtained from Invitrogen; Thermo Fisher Scientific, Inc. Transwell assay kit was obtained from ElabScience Biotechnology, Co., Ltd. Primers, transfection plasmids of miR-212-3p and SOX11, and internal references (U6 and GAPDH) were designed and synthesized by Sangon Biotech Co., Ltd. The mimic control (scrambled) was purchased from Shanghai GenePharma Co., Ltd. The sequences of the mimics were as follows: miR-212-3p mimic sense, 5'-UAACAGUCUCCAGUCACGGGG-3' and antisense, 5'-CCGUGACUGGAGACUGUUAUU-3'; and mimic control (miR-NC) sense, 5'-UUCUCCGAACGCGUG UCACGUTT-3' and antisense, 5'-ACGUGACACGUUCGG AGAATT-3'. The equipment included an ultraviolet spectrophotometer (Thermo Fisher Scientific Inc.), a flow cytometer (CoulterCytoFLEX; Beckman Coulter, Inc.), an ABI 7500 FAST Real-Time PCR instrument (ABI 7500; Applied Biosystems; Thermo Fisher Scientific, Inc.).

Determination of miR-212-3p and SOX11 mRNA expression. Total RNA was extracted from patient cancerous tissues and transfected cells in each group using TRIzol reagent (Invitrogen; Thermo Fisher Scientific, Inc.) in accordance with the manufacturer's instructions. cDNA was synthesized using the PrimeScript ${ }^{\circledR} \mathrm{RT}$ reagent kit according to the manufacturer's protocol. (Takara Bio, Inc.). RT-qPCR was performed using SYBR Premix ExTaq ${ }^{\mathrm{TM}}$ (Takara Bio, Inc.) on the platform of Applied Biosystems 7500 (Applied Biosystems; Thermo Fisher Scientific, Inc.). U6 and GAPDH were used as internal controls for miRNA and mRNA, respectively. The reverse universal miR qPCR primers were included in the PrimeScript ${ }^{\mathrm{TM}}$ miRNA RT-PCR kit (cat. no. RR716; Takara Biotechnology Co., Ltd.). The total reaction system was $20 \mu \mathrm{l}$ in volume, containing $1 \mu \mathrm{l}$ cDNA, $10 \mu \mathrm{l}$ SYBR Premix EX Taq, $1 \mu$ l each of the primers $(10 \mu \mathrm{M})$ and $7 \mu \mathrm{lddH_{2 }} \mathrm{O}$. The PCR program was as follows: $95^{\circ} \mathrm{C}$ for $3 \mathrm{~min}$, followed by 40 cycles of $95^{\circ} \mathrm{C}$ for $10 \mathrm{sec}$ and $60^{\circ} \mathrm{C}$ for $30 \mathrm{sec}$. Primers were synthesized by Sangon Biotech Co., Ltd., as follows: miR-221-3p forward, 5'-CGGCTACAT TGTCTGCCTG-3' and reverse, 5'-CAGTGCGTGTCGTGG
Table I. Clinical characteristics of the patients with mantle cell lymphoma $(\mathrm{n}=65)$.

\begin{tabular}{lc}
\hline Characteristics & Values \\
\hline Sex, n $(\%)$ & \\
Male & $35(53.85)$ \\
Female & $30(46.15)$ \\
Mean age $\pm \mathrm{SD}$, years & $45.23 \pm 12.31$ \\
Mean BMI $\pm \mathrm{SD}, \mathrm{kg} / \mathrm{m}^{2}$ & $23.23 \pm 0.87$ \\
Lymphoma and the location of & \\
adjacent tissues, $\mathrm{n}(\%)$ & \\
Colorectal & $18(27.70)$ \\
Stomach & $17(26.15)$ \\
Torso skin & $20(30.77)$ \\
Marrow & $10(15.38)$ \\
\hline
\end{tabular}

AGT-3'; SOX11 forward, 5'-AGCAAGAAATGCGGCAAGC-3' and reverse, 5'-ATCCAGAAACACGCACTTGAC-3'; GAPDH forward, 5'-GGAGCGAGATCCCTCCAAAAT-3' and reverse, 5'-GGCTGTTGTCATACTTCTCATGG-3'; and U6 forward, 5'-CGCTTCGGCAGCACATATAC-3' and reverse, 5'-AAC GCTTCACGAATTTGCGT-3'. The relative expression levels of miR-221-3p and SOX11 were calculated using the $2^{-\Delta \Delta C q}$ method (21). All experiments were conducted in triplicate.

Determination of SOX11 protein expression. Total protein from patient cancerous tissues and transfected cells was lysed with RIPA buffer (Invitrogen; Thermo Fisher Scientific, Inc.), and protein concentration was measured using a BCA kit (Beyotime Institute of Biotechnology). Total protein (50 $\mu \mathrm{g} /$ lane) was separated by $10 \%$ SDS-PAGE and blotted onto polyvinylidene fluoride membranes. After blocking in $5 \%$ skimmed milk for $1 \mathrm{~h}$ at room temperature, the membranes were incubated overnight at $4{ }^{\circ} \mathrm{C}$ with primary antibodies against $\operatorname{SOX} 2$ (1:1,000; cat. no. ab170916; Abcam) and $\beta$-actin (1:1,000; cat. no. ab6276; Abcam). Subsequently, secondary horse-radish peroxidase (HRP)-rabbit antibodies were incubated with the membranes at room temperature for $2 \mathrm{~h}(1: 5,000$; cat. no. ab6858; Abcam). The bands were visualized using an ECL kit (Beyotime Institute of Biotechnology), and the gray values of the bands were calculated automatically using the Image J software version k1.45 (National Institutes of Health). SOX11/GAPDH ratios represented relative protein expression.

Cell culture and transfection. JeKo-1 and Z-138 cells were sub-cultured routinely in high-sugar DMEM containing $10 \% \mathrm{FBS}$ in a $5 \% \mathrm{CO}_{2}$ cell incubator at $37^{\circ} \mathrm{C}$. After culture, the cells were divided into the miR-NC and miR-212-3p mimic groups before being seeded into a 96-well plate, and cells were then transfected with the miR-NC or miR-212-3p mimic at a concentration of $80 \mathrm{nmol} / \mathrm{ml}$ using Lipofectamine $3000^{\circledR}$ at $37^{\circ} \mathrm{C}$ for $24 \mathrm{~h}$. miR-212-3p expression in each group was detected $24 \mathrm{~h}$ after transfection.

Cell proliferation assay. Transfected JeKo-1 and Z-138 cells in the two groups were seeded $\left(4 \times 10^{3} /\right.$ well) into a 96 -well 
A

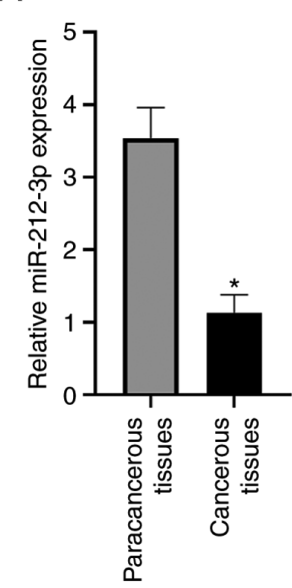

B

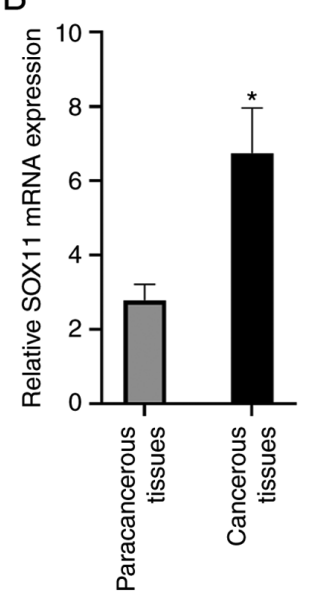

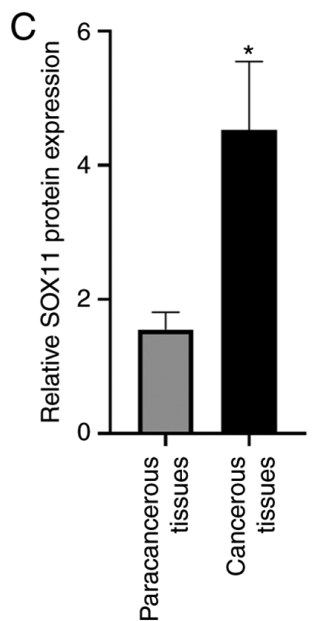
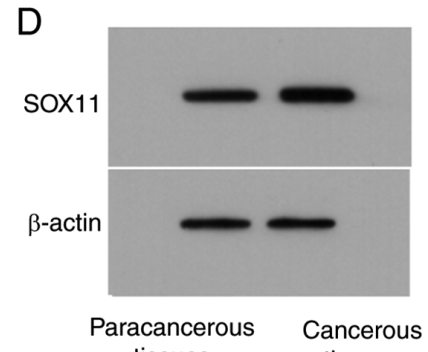

tissues tissues

Figure 1. Relative miR-212-3, SOX11 mRNA and protein expression in cancerous and paracancerous tissues. (A) Relative mRNA expression levels of miR-212-3p in paracancerous and cancerous tissues. Relative SOX11 (B) mRNA and (C and D) protein expression in the cancerous and paracancerous tissues. ${ }^{*} \mathrm{P}<0.05$ vs. paracancerous tissues. miR, microRNA; SOX11, sex-determining region Y-box 11.

plate separately, and each sample was tested in three duplicate wells. Subsequently, the plate was cultured for 24,48 and $72 \mathrm{~h}$. A total of $10 \mu \mathrm{l} \mathrm{CCK8} \mathrm{reagent} \mathrm{from} \mathrm{the} \mathrm{cell} \mathrm{proliferation} \mathrm{colo-}$ rimetric assay kit (CCK8; Shanghai Xiangsheng Biological Technology Co., Ltd.) was added to each well $2 \mathrm{~h}$ before the end of culture period. After addition of the reagent at each time-point, the plate was cultured in a $5 \% \mathrm{CO}_{2}$ cell incubator at $37^{\circ} \mathrm{C}$ for $2 \mathrm{~h}$, and the optical density of each well was measured at $490 \mathrm{~nm}$ using an automatic microplate reader to analyze cell proliferation.

Cell invasion assay. To detect cell migration, the Transwell assay was performed. First, matrix gelatin $(10 \mu \mathrm{g} / \mu \mathrm{l})$ was melted at $4^{\circ} \mathrm{C}$, diluted to $0.25 \mu \mathrm{g} / \mu 1$ with DMEM, and stored in an ice box for future use. Subsequently, $100 \mu 1$ of diluted matrix gelatin was added to each well of the 24-well Transwell insert, and the insert was cultured in a $5 \% \mathrm{CO}_{2}$ incubator at $37^{\circ} \mathrm{C}$ for $1 \mathrm{~h}$. After the matrix gel solidified to form the mechanical barrier layer, the remaining uncured liquid was absorbed using filter paper. Subsequently, cells in each group were transferred to the insert. DMEM $(100 \mu \mathrm{l})$ with $10 \%$ FBS was added to the upper chamber and DMEM $(600 \mu \mathrm{l})$ with $20 \%$ FBS was added to the lower chamber (22). The upper chamber (coated with Matrigel) was filled with cells $\left(4 \times 10^{3}\right.$ cells/well). Finally, the cells were incubated in a $5 \% \mathrm{CO}_{2}$ incubator at $37^{\circ} \mathrm{C}$ for 1 day. Paraformaldehyde (4\%) was used to fix the cells at $4^{\circ} \mathrm{C}$ for $20 \mathrm{~min}$ that were being moved via the membrane and crystal violet hydrate solution was used to dye them (Shanghai Yuanye Biological Technology Co., Ltd.), and counted under a light microscope (Leica Microsystems) (magnification, x100) after $24 \mathrm{~h}$ incubation period at room temperate.

Apoptosis assay. Cells were transfected for $48 \mathrm{~h}$ and were stained with Annexin V and PI (cat. no. V13241; BD Biosciences) in a 6 -well plate for $30 \mathrm{~min}$ at $4^{\circ} \mathrm{C}$. Subsequently, cells were detected using a CoulterCytoFLEX flow cytometer (Beckman Coulter, Inc.), and the assay was repeated three times. FlowJo v.10 (Flowjo LLC) was used for analysis.
Bioinformatics analysis. To identify the putative miRNA target, the online miRNA target analysis tools TargetScanHuman v.7.2 (http://www.targetscan.org/vert_70/) was used.

Verification of the targeting association between $\mathrm{miR}-212-3 p$ and SOX11 using a dual luciferase reporter gene assay. JeKo-1 and Z-138 cells $\left(4 \times 10^{3}\right.$ cells/well) were seeded into a 96-well plate, The SOX11 mutated and SOX11 wild-type (WT) 3'UTR was also added to the Luciferase miRNA expression reporter (Promega Inc.) and miR-212-3p mimics, SOX11 mutated and SOX11 wild-type (WT) were transfected into the cells using Lipofectamine 3000, as aforementioned. After $48 \mathrm{~h}$ of transfection Firefly and Renilla luciferase activities in the cells were determined using a dual luciferase reporter assay kit (Promega Corporation). The Firefly luciferase activities were normalized to Renilla luciferase activity and the relative luciferase activity of Firefly (to Renilla) were reported in the present study. Each assay was repeated thrice.

Statistical analysis. Statistical analyses were performed using SPSS 19.0 (IBM Corp.). Comparisons between tumor and normal tissues were analyzed using a paired t-test, while comparisons between transfection groups were analyzed using an unpaired t-test and one-way or two-way ANOVA with Bonferroni correction as the post hoc test. The values were expressed as the mean \pm SE. Each experiment was performed independently at least 3 times. Count data were analyzed using the $\chi^{2}$ test. $\mathrm{P}<0.05$ was considered to indicate a statistically significant difference.

\section{Results}

miR-212-3p and SOX11 expression in paracancerous and cancerous tissues. miR-212-3p expression in the paracancerous tissues was significantly higher than that in the cancerous tissues $(3.54 \pm 0.42$ vs. $1.13 \pm 0.25$; $\mathrm{P}<0.0015$; Fig. 1$)$. The relative SOX11 mRNA expression in the paracancerous and cancerous tissues was $2.78 \pm 0.43$ and $6.74 \pm 1.22$, respectively, and the relative SOX11 protein expression was 

A SoX11-Mut $\downarrow \quad 5^{\prime}$...CCUUUUGGCAGCACAUGACAAC... SOX11-wt $\downarrow \quad 5^{\prime} \ldots$...CUUUUGGCAGCACAACUGUUAC... $\downarrow$ IIIIII hsa-miR-212-3p $\quad 3^{\prime} \quad$ CCGGCACUGACCUCUGACAAU

$\mathrm{B}$

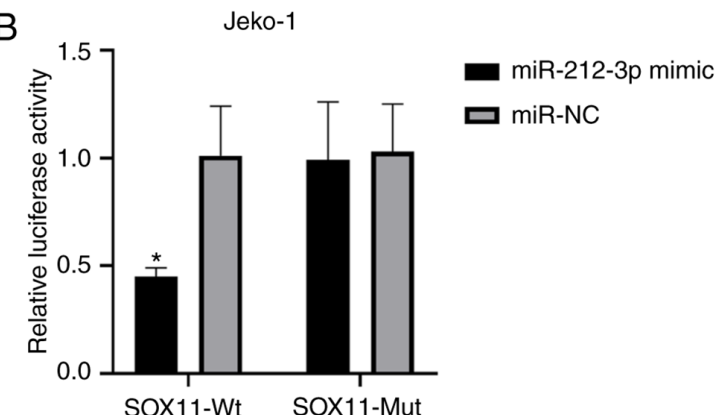

C

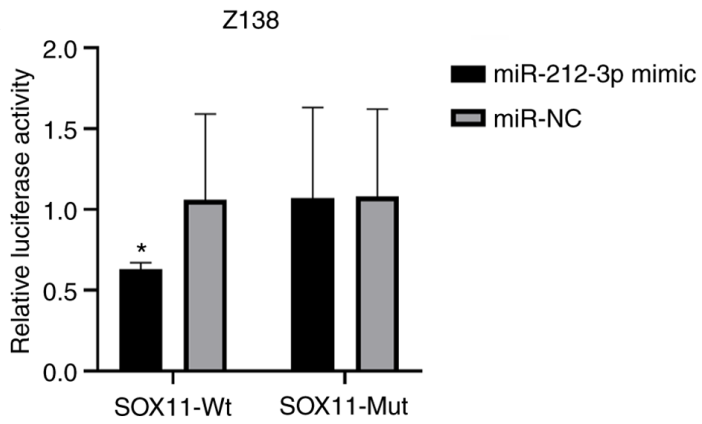

Figure 2. Binding loci and luciferase activity between miR-212-3p and SOX11. (A) Binding loci between miR-212-3p and SOX11. Luciferase activity was measured in (B) Jeko-1 and (C) Z138 cells following transfection with miR-212-3p mimics or miR-NC and SOX11-WT or SOX11-Mut. "P<0.05 vs. miR-NC group. miR, microRNA; SOX11, sex-determining region Y-box 11; NC, negative control; WT, wild-type; Mut, mutated.
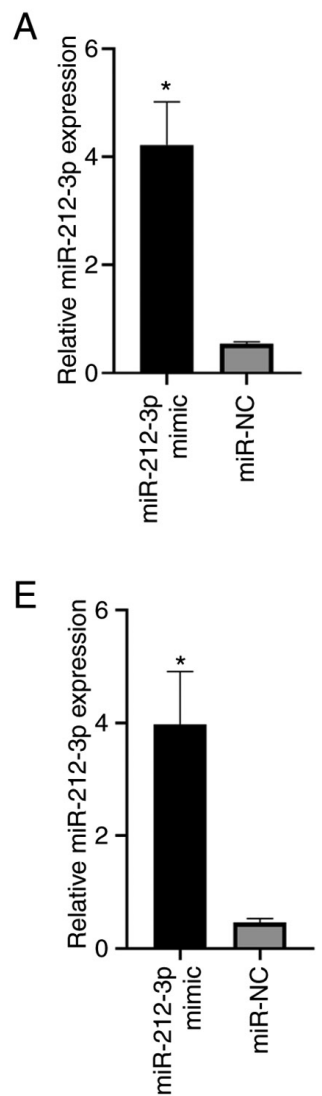
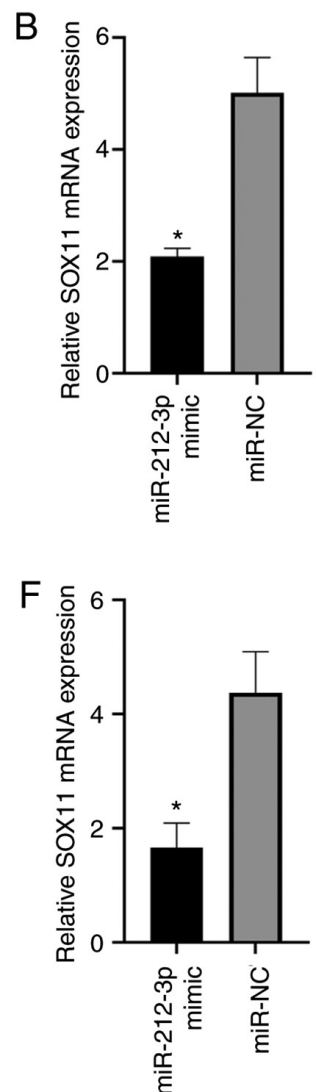

JeKo-1

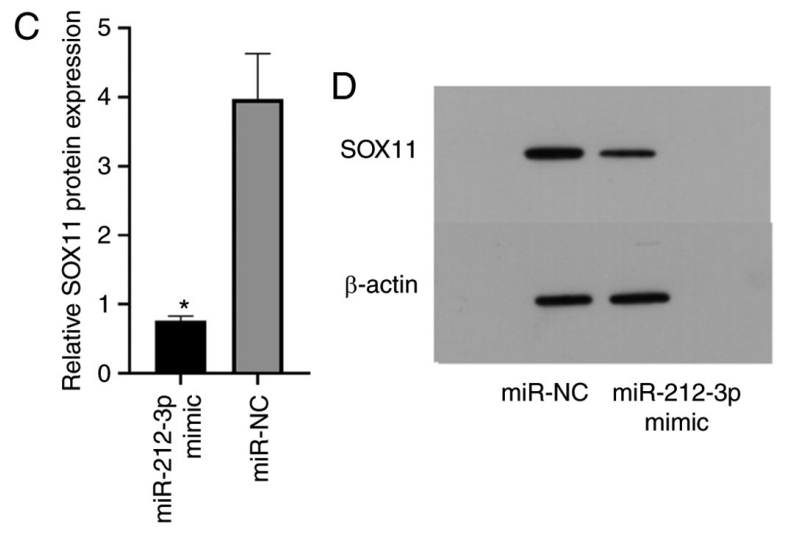

Z138

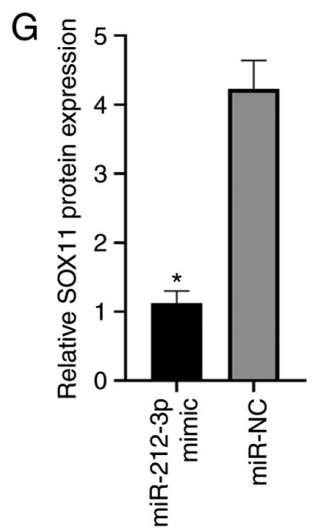

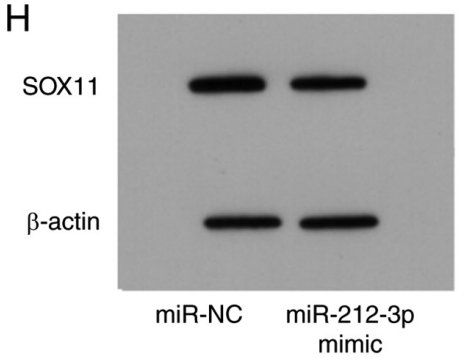

Figure 3. Relative expression levels of miR-212-3p, mRNA and protein expression levels of SOX11 between the miR-212-3p mimic and the miR-NC groups in Jeko-1 cells or Z138 cells. (A) Relative expression levels of miR-212-3p, (B) mRNA and (C and D) protein expression levels of SOX11 between the miR-212-3p mimic and the miR-NC groups in Jeko-1 cells. (E) Relative expression levels of miR-212-3p, (F) mRNA and (G and H) protein expression levels of SOX11 between the miR-212-3p mimic and the miR-NC groups in Z138 cells. " $\mathrm{P}<0.05$ vs. miR-NC group. miR, microRNA; SOX11, sex-determining region Y-box 11; NC, negative control.

$1.55 \pm 0.26$ and $4.53 \pm 1.02$, respectively; thus, relative SOX11 mRNA and protein expression in the cancerous tissues was significantly higher than that in the paracancerous tissues (both $\mathrm{P}<0.05$; Fig. 1). The current results indicated that miR-212-3p expression may be negatively associated with lymphoma, suggesting that miR-212-3p may have an inhibitory effect on lymphoma. Both mRNA and protein expression levels of SOX11 were high in the cancerous tissues, suggesting that SOX11 may serve an important role in lymphoma. 
A

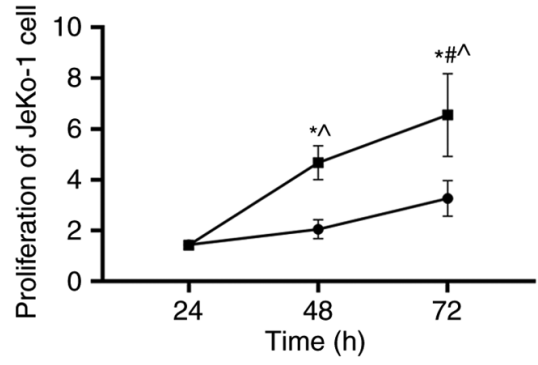

B

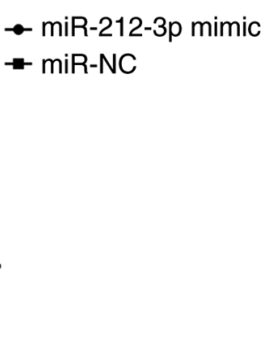

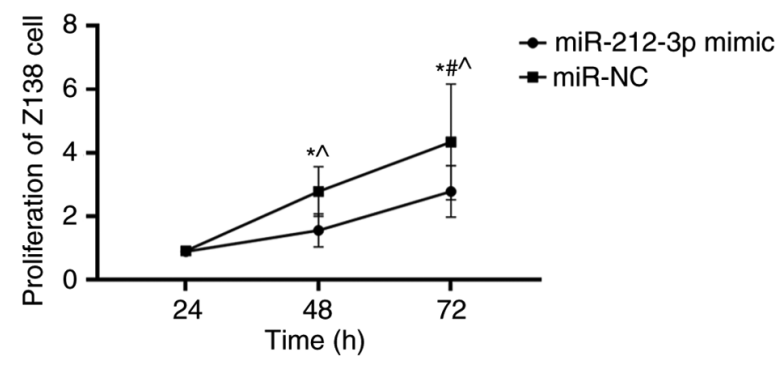

Figure 4. Proliferation of human mantle cell lymphoma JeKo-1 and Z138 cells in the miR-212-3p mimic and the miR-NC groups. Proliferation of human mantle cell lymphoma (A) JeKo-1 and (B) Z138 cells in the miR-212-3p mimic and the miR-NC groups. * P<0.05 vs. miR-212-3p mimic group; ${ }^{\wedge} \mathrm{P}<0.05$ vs. 24 h; ${ }^{~} \mathrm{P}<0.05$ vs. 48 h. miR, microRNA; NC, negative control.

Targeting association between $\mathrm{miR}-212-3 p$ and SOX11. As predicted with TargetScanHuman v.7.2, binding loci were found between miR-212-3p and SOX11 (Fig. 2A). The binding between SOX11 and miR-212-3p significantly decreased the luciferase activity in the SOX11-Wt and miR-212-3p mimic group ( $\mathrm{P}<0.05$; Fig. 2B and $\mathrm{C})$. Therefore, miR-212-3p targeted regulation of SOX11, and it was speculated that miR-212-3p may serve an important role in lymphoma by regulating SOX11.

Elevated SOX11 expression after miR-212-3p overexpression. As shown in the experimental results, the miR-212-3p mimic group exhibited significantly higher miR-212-3p expression than the miR-NC group (JeKo-1, 4.22 \pm 0.80 vs. $0.54 \pm 0.04 ; \mathrm{Z}-138,3.97 \pm 0.94$ vs. $0.46 \pm 0.07 ; \mathrm{P}<0.05$; Fig. 3A and E). Additionally, SOX11 mRNA expression in the miR-212-3p mimic group was significantly lower than that in the miR-NC group (JeKo-1, $2.08 \pm 0.15$ vs. $5.01 \pm 0.63 ; \mathrm{Z}-138$, $1.66 \pm 0.43$ vs. $4.37 \pm 0.72$; $P<0.05$; Fig. $3 B$ and F). Similarly, SOX11 protein expression in the miR-212-3p mimic group was significantly lower than that in the miR-NC group (JeKo-1, $0.76 \pm 0.07$ vs. $3.97 \pm 0.66 ; \mathrm{Z}-138,1.12 \pm 0.18$ vs. $4.23 \pm 0.41$; $\mathrm{P}<0.05$; Fig. 3C, D, G and $\mathrm{H}$ ). The current results indicated that miR-212-3p may have an inhibitory effect on SOX11.

miR-212-3p overexpression decreases the proliferation of JeKo-1 and Z-138 cells. At $24 \mathrm{~h}$, cell proliferation in the miR-212-3p mimic group was not significantly different from that in the miR-NC group ( $\mathrm{P}>0.05$; Fig. 4). However, at 48 and $72 \mathrm{~h}$, the miR-212-3p mimic group exhibited significantly decreased cell proliferation than the miR-NC group $(\mathrm{P}<0.05$; Fig. 4). The proliferation of lymphatic cancer cells was slowed down, indicating that miR-212-3p may affect the proliferation of lymphatic cancer cells by inhibiting SOX11.

miR-212-3p overexpression decreases the migration of JeKo-1 and Z-138 cells. The number of migrating cells in the miR-212-3p mimic group was significantly lower than that in the miR-NC group (JeKo-1, 78.56 \pm 7.25 vs. $139.78 \pm 11.98$ cells; Z-138, 55.23 \pm 8.67 vs. 132.55 \pm 13.36 ; P<0.05; Fig. 5). The slowing down of the migration rate of the lymphatic cancer JeKo-1 and Z-138 cells indicated that miR-212-3p may affect the migration of lymphatic cancer cells by inhibiting SOX11.
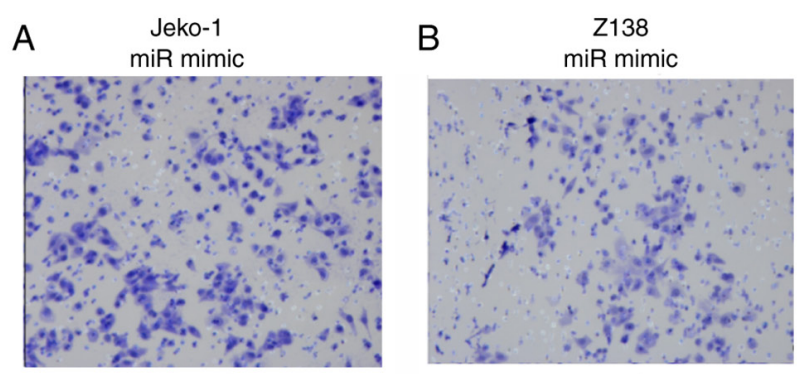

miR-NC
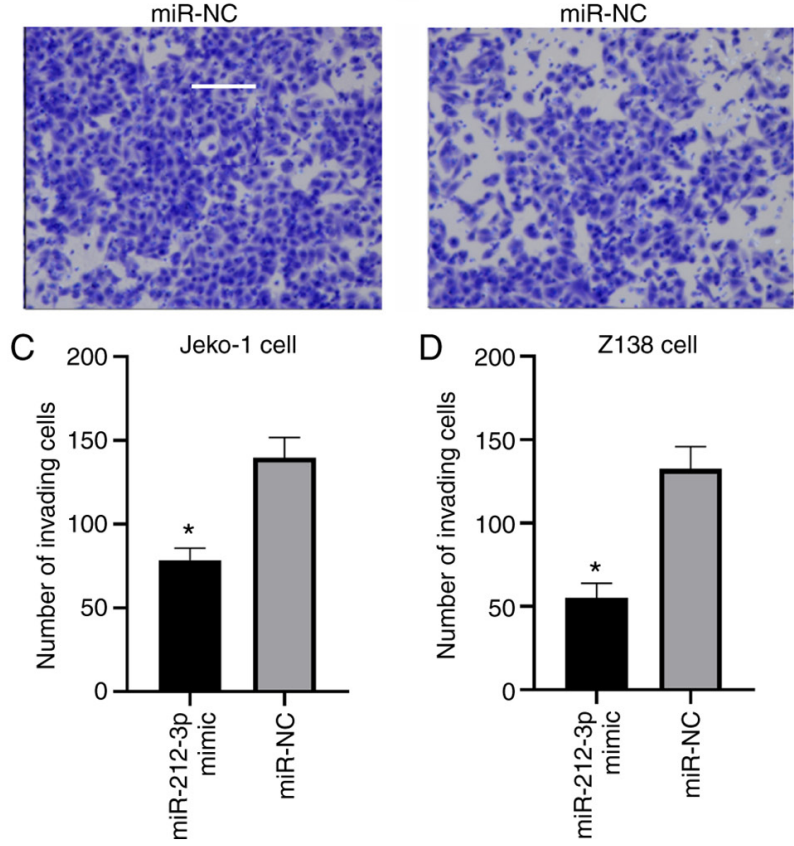

Figure 5. Invasion of human mantle cell lymphoma JeKo-1 and Z138 cells Invasion of human mantle cell lymphoma (A) JeKo-1 and (B) Z138 cells analyzed by Transwell assay (scale bar, $50 \mu \mathrm{m}$ ) and quantification of invading (C) JeKo-1 and (D) Z138 cells in the miR-212-3p mimic and the miR-NC groups. ${ }^{*} \mathrm{P}<0.05$ vs. miR-NC group. miR, microRNA; NC, negative control.

miR-212-3p overexpression increased the apoptosis of JeKo-1 and Z-138 cells. The miR-212-3p mimic group exhibited a significantly higher apoptotic rate than the miR-NC group (JeKo-1, $27.25 \pm 2.34 \%$ vs. $5.51 \pm 0.74 \%$; Z-138, $23.12 \pm 3.11 \%$ vs. $4.32 \pm 1.55 \%$; $\mathrm{P}<0.001$; Fig. 6). The increase in the apoptotic rate of the lymphatic cancer JeKo-1 and Z-138 cells indicated that miR-212-3p may affect the apoptosis of lymphatic cancer cells by inhibiting SOX11. 
A
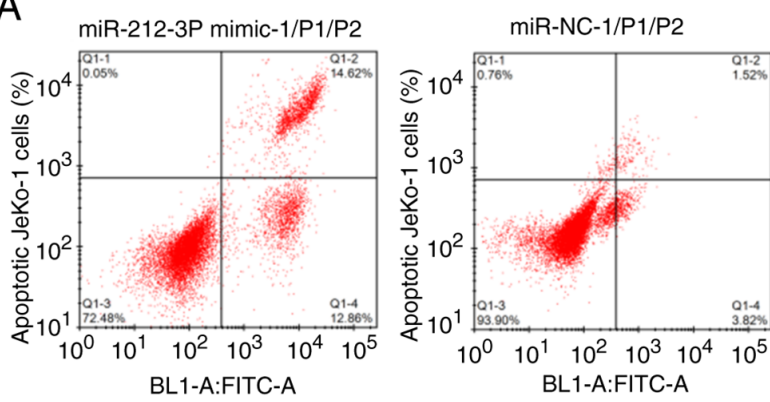

C

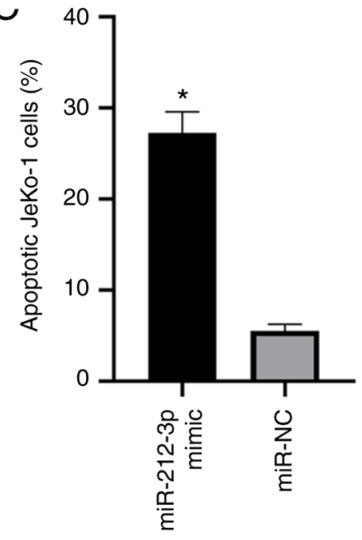

B
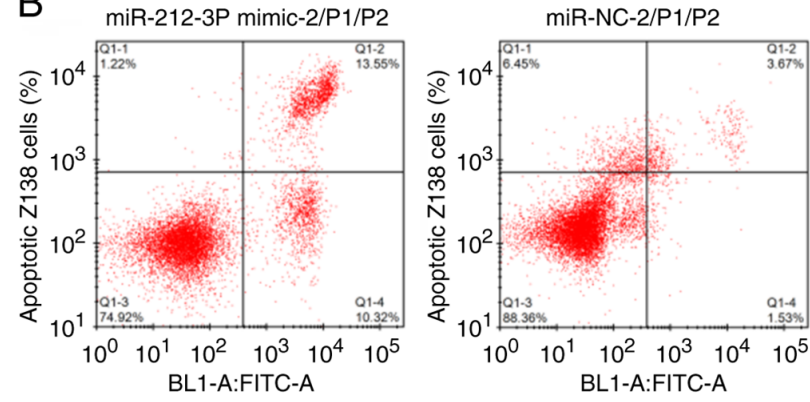

D

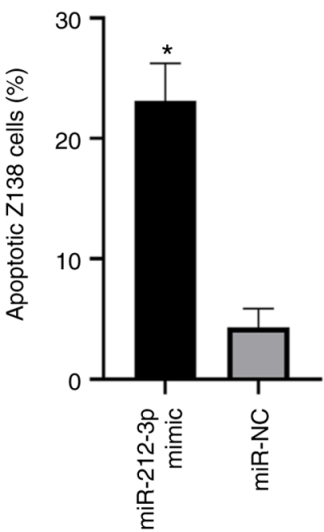

Figure 6. Apoptosis of human mantle cell lymphoma JeKo-1 and Z138 cells. Apoptosis of human mantle cell lymphoma (A) JeKo-1 and (B) Z138 cells analyzed by flow cytometry and quantification of apoptotic (C) JeKo-1 and (D) Z138 cells in the miR-212-3p mimic and the miR-NC groups. "P<0.05 vs. miR-NC group. miR, microRNA; NC, negative control.

\section{Discussion}

At present, chemotherapy and immunotherapy for MCL have greatly improved; however, an increasing number of patients has been estimated to die of MCL recurrence after surgery (23). Thus, the treatment methods and prognosis for patients with MCL should be urgently improved. Targeted therapy against SOX11 may be a good method for MCL management (24); therefore, the present study aimed to explore the association between miR-212-3p and SOX11.

In some lymphomas compared with normal tissue, miR-212-3p expression is downregulated, whereas in MCL, SOX11 expression is upregulated $(17,25)$. Therefore, miR-212-3p and SOX11 may be negatively associated in MCL. The results of the current study revealed that miR-212-3p expression in cancerous tissues was significantly lower than that in the paracancerous tissues, while SOX11 expression was significantly increased in cancerous tissues compared with in paracancerous tissues, suggesting that SOX11 and miR-212-3p may be negatively associated.

According to previous studies, miR-212-3p hinders the progression of some types of cancer, including pancreatic and bladder cancer $(19,26)$. The present study suggested a negative association between SOX11 and miR-212-3p expression, although whether this association was targeted was unclear. A study on epilepsy has revealed that miR-212-3p inhibits further deterioration of the disease by targeting SOX11 (27). Therefore, SOX11 expression was detected in cells transfected with miR-212-3p mimics, revealing that SOX11 expression was decreased following miR-212-3p overexpression. Therefore,
miR-212-3p and SOX11 exhibited a targeting inhibitory association.

SOX11 expression has different roles in various types of cancer (28). SOX11 overexpression inhibits the proliferation, invasion and apoptosis of ovarian and prostate cancer cells $(10,29)$. However, SOX11 overexpression promotes the proliferation and invasion in different head cell carcinoma cells, such as thyroid carcinoma and lymphoma cells, such as MCL (30). By contrast, SOX11 inhibition leads to the opposite effects $(9,31,32)$. Therefore, modulation of SOX11 expression has different effects in various types of cancer. Moreover, according to the current results, miR-212-3p inhibited SOX11 in a targeted manner. For verification, the present study determined and analyzed the targeted inhibition of SOX11 by miR-212-3p, and analyzed the effects of miR-212-3p on the proliferation, migration and apoptosis of lymphoma cells. Consequently, cells in the miR-212-3p mimic group exhibited lower proliferation and migration, and higher apoptotic rates than those in the miR-NC group. According to the current results miR-212-3p may serve a targeted inhibitory role against SOX11. miR-212-3p overexpression resulted in decreased SOX11 expression, leading to decreased proliferation and migration of lymphoma cells and elevated apoptosis. miR-212-3p specifically inhibited SOX11. The current findings provide insights into novel molecular therapy schemes. However, although high SOX11 expression was demonstrated in cancerous tissues compared with in paracancerous tissues, due to constraints in time and technologies, experiments analyzing SOX11 expression under miR-212-3p inhibition, as well as experiments to prove changes in cell proliferation, 
migration and apoptosis under SOX11 overexpression were not performed in the present study. Therefore, further studies should be performed in the future to confirm the current results.

In conclusion, miR-212-3p inhibited cell proliferation and migration, and promoted the apoptosis of lymphoma cells by specifically regulating SOX11; thus, miR-212-3p may serve as a novel therapeutic target and marker for lymphoma.

\section{Acknowledgements}

Not applicable.

\section{Funding}

The present study was supported by the Research Project of Xuzhou Medical College (grant no. 2018KJ11), the Natural Science Foundation of Huai'an, Jiangsu (grant no. HAB201814), Jiangsu Provincial Commission of Health and Family Planning (grant no. H201556), the Six Top Talent Peak Projects in Jiangsu (grant no. WSN-019) and the 333 Talent Project of Jiangsu Province (grant no. BRA2017246).

\section{Availability of data and materials}

The datasets used and/or analyzed during the current study are available from the corresponding author on reasonable request.

\section{Authors' contributions}

YT, LW and GL conceived and designed the research, and interpreted the results of the experiments. YZ and YF performed the experiments. LL and XZ analyzed the data. GL prepared the figures and drafted, edited and revised the manuscript. YT and LW confirmed the authenticity of all the raw data. All authors read and approved the final version of the manuscript.

\section{Ethics approval and consent to participate}

The Ethics Committee of Huai'an Hospital Affiliated to Xuzhou Medical College and Huai'an Second People's Hospital (Huai'an, China) approved the present study. All patients and their families were informed of the study, and they signed informed consent forms before the commencement of the study.

\section{Patient consent for publication}

Not applicable.

\section{Competing interests}

The authors declare that they have no competing interests.

\section{References}

1. Cheah CY, Seymour JF and Wang ML: Mantle cell lymphoma. J Clin Oncol 34: 1256-1269, 2016.

2. Robak T, Huang H, Jin J, Zhu J, Liu T, Samoilova O, Pylypenko H, Verhoef G, Siritanaratkul N, Osmanov E, et al: Bortezomib-based therapy for newly diagnosed mantle-cell lymphoma. N Engl J Med 372: 944-953, 2015.
3. Vose JM: Mantle cell lymphoma: 2013 Update on diagnosis, risk-stratification, and clinical management. Am J Hematol 88: 1082-1088, 2013.

4. Pérez-Galán P, Dreyling M and Wiestner A: Mantle cell lymphoma: Biology, pathogenesis, and the molecular basis of treatment in the genomic era. Blood 117: 26-38, 2011.

5. Mohanty A, Sandoval N, Das M, Pillai R, Chen L, Chen RW, Amin HM, Wang M, Marcucci G, Weisenburger DD, et al: CCND1 mutations increase protein stability and promote ibrutinib resistance in mantle cell lymphoma. Oncotarget 7: 73558-73572, 2016.

6. Dreyling M and Ferrero S; European Mantle Cell Lymphoma Network: The role of targeted treatment in mantle cell lymphoma: Is transplant dead or alive? Haematologica 101: 104-114, 2016.

7. Beà S and Amador V: Role of SOX11 and genetic events cooperating with cyclin D1 in mantle cell lymphoma. Curr Oncol Rep 19: 43, 2017.

8. Lord M, Wasik AM, Christensson B and Sander B: The utility of mRNA analysis in defining SOX11 expression levels in mantle cell lymphoma and reactive lymph nodes. Haematologica 100: e369-e372, 2015.

9. Palomero J, Vegliante MC, Eguileor A, Rodriguez ML, Balsas P, Martinez D, Campo E and Amador V: SOX11 defines two different subtypes of mantle cell lymphoma through transcriptional regulation of BCL6. Leukemia 30: 1596-1599, 2016.

10. Fang G, Liu J, Wang Q, Huang X, Yang R, Pang Y and Yang M: MicroRNA-223-3p regulates ovarian cancer cell proliferation and invasion by targeting SOX11 expression. Int J Mol Sci 18: 1208, 2017.

11. Shepherd JH, Uray IP, Mazumdar A, Tsimelzon A, Savage M, Hilsenbeck SG and Brown PH: The SOX11 transcription factor is a critical regulator of basal-like breast cancer growth, invasion, and basal-like gene expression. Oncotarget 7: 13106-13121, 2016.

12. Palomero J, Vegliante MC, Rodríguez ML, Eguileor Á, Castellano G, Planas-Rigol E, Jares P, Ribera-Cortada I, Cid MC, Campo E and Amador V: SOX11 promotes tumor angiogenesis through transcriptional regulation of PDGFA in mantle cell lymphoma. Blood 124: 2235-2247, 2014.

13. Balsas P, Palomero J, Eguileor Á, Rodríguez ML, Vegliante MC, Planas-Rigol E, Sureda-Gómez M, Cid MC, Campo E and Amador V: SOX11 promotes tumor protective microenvironment interactions through CXCR4 and FAK regulation in mantle cell lymphoma. Blood 130: 501-513, 2017.

14. Zhang X, Gee H, Rose B, Lee CS, Clark J, Elliott M, Gamble JR, Cairns MJ, Harris A, Khoury S and Tran N: Regulation of the tumour suppressor PDCD4 by miR-499 and miR-21 in oropharyngeal cancers. BMC Cancer 16: 86, 2016.

15. Volinia S, Calin GA, Liu CG, Ambs S, Cimmino A, Petrocca F, Visone R, Iorio M, Roldo C, Ferracin M, et al: A microRNA expression signature of human solid tumors defines cancer gene targets. Proc Natl Acad Sci USA 103: 2257-2261, 2006.

16. Wang H, Guo Q, Yang $\mathrm{P}$ and Long G: Restoration of microRNA-212 causes a G0/G1 cell cycle arrest and apoptosis in adult T-cell leukemia/lymphoma cells by repressing CCND3 expression. J Investig Med 65: 82-87, 2017.

17. Ambrosio MR, Mundo L, Gazaneo S, Picciolini M, Vara PS, Sayed S, Ginori A, Lo Bello G, Del Porro L, Navari M, et al: MicroRNAs sequencing unveils distinct molecular subgroups of plasmablastic lymphoma. Oncotarget 8: 107356-107373, 2017.

18. Ju C, Zhou R, Sun J, Zhang F, Tang X, Chen KK, Zhao J, Lan X, Lin S, Zhang Z and Lv XB: LncRNA SNHG5 promotes the progression of osteosarcoma by sponging the miR-212-3p/SGK3 axis. Cancer Cell Int 18: 141, 2018.

19. Liu H, Li C, Shen C, Yin F, Wang K, Liu Y, Zheng B, Zhang W, Hou X, Chen X, et al: miR-212-3p inhibits glioblastoma cell proliferation by targeting SGK3. J Neurooncol 122: 431-439, 2015.

20. Hou P, Kang Y and Luo J: Hypoxia-mediated miR-212-3p downregulation enhances progression of intrahepatic cholangiocarcinoma through upregulation of Rabla. Cancer Biol Ther 19: 984-993, 2018

21. Livak KJ and Schmittgen TD: Analysis of relative gene expression data using real-time quantitative PCR and the 2(-Delta Delta C(T)) Method. Methods 25: 402-408, 2001.

22. Yuan S, Dong Y, Peng L, Yang M, Niu L, Liu Z and Xie J: Tumor-associated macrophages affect the biological behavior of lung adenocarcinoma A549 cells through the PI3K/AKT signaling pathway. Oncol Lett 18: 1840-1846, 2019.

23. Danilov AV and Persky DO: Incorporating acalabrutinib, a selective next-generation Bruton tyrosine kinase inhibitor, into clinical practice for the treatment of haematological malignancies. Br J Haematol 193: 15-25, 2021. 
24. Kuo PY, Leshchenko VV, Fazzari MJ, Perumal D, Gellen T, He T, Iqbal J, Baumgartner-Wennerholm S, Nygren L, Zhang F, et al: High-resolution chromatin immunoprecipitation (ChIP) sequencing reveals novel binding targets and prognostic role for SOX11 in mantle cell lymphoma. Oncogene 34: 1231-1240, 2015

25. Beekman R, Amador V and Campo E: SOX11, a key oncogenic factor in mantle cell lymphoma. Curr Opin Hematol 25: 299-306, 2018.

26. Xia L, Li D, Lin C, Ou S, Li X and Pan S: Comparative study of joint bioinformatics analysis of underlying potential of 'neurimmiR', $\mathrm{miR}-212-3 \mathrm{P} / \mathrm{miR}-132-3 \mathrm{P}$, being involved in epilepsy and its emerging role in human cancer. Oncotarget 8: 40668-40682, 2017.

27. Haenisch S, Zhao Y, Chhibber A, Kaiboriboon K, Do LV, Vogelgesang S, Barbaro NM, Alldredge BK, Lowenstein DH, Cascorbi I and Kroetz DL: SOX11 identified by target gene evaluation of miRNAs differentially expressed in focal and non-focal brain tissue of therapy-resistant epilepsy patients. Neurobiol Dis 77: 127-140, 2015

28. Yang Z, Jiang S, Lu C, Ji T, Yang W, Li T, Lv J, Hu W, Yang Y and Jin Z: SOX11: Friend or foe in tumor prevention and carcinogenesis? Ther Adv Med Oncol 11: 1758835919853449, 2019.
29. Yao Z, Sun B, Hong Q, Yan J, Mu D, Li J, Sheng H and Guo H: The role of tumor suppressor gene SOX11 in prostate cancer. Tumour Biol 36: 6133-6138, 2015.

30. Tsang SM, Oliemuller E and Howard BA: Regulatory roles for SOX11 in development, stem cells and cancer. Semin Cancer Biol 67: 3-11, 2020.

31. Huang J, Ji EH, Zhao X, Cui L, Misuno K, Guo M, Huang Z, Chen X and Hu S: Sox11 promotes head and neck cancer progression via the regulation of SDCCAG8. J Exp Clin Cancer Res 38: $138,2019$.

32. Wang L, Shen YF, Shi ZM, Shang XJ, Jin DL and Xi F: Overexpression miR-211-5p hinders the proliferation, migration, and invasion of thyroid tumor cells by downregulating SOX. J Clin Lab Anal 32: e22293, 2018.

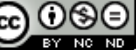

\footnotetext{
This work is licensed under a Creative Commons Attribution-NonCommercial-NoDerivatives 4.0 International (CC BY-NC-ND 4.0) License.
} 